\title{
MINERALIZAÇÃO DO CARBONO DA PALHA DE AVEIA E DEJETOS DE SUÍNOS APLICADOS NA SUPERFÍCIE OU INCORPORADOS AO SOLO ${ }^{(1)}$
}

\author{
Sandro José Giacomini ${ }^{(2)}$, Celso Aita ${ }^{(3)}$, Ezequiel César Carvalho Miola ${ }^{(4)}$ \& Sylvie Recous $^{(5)}$
}

\begin{abstract}
RESUMO
A mineralização do $\mathrm{C}$ de dejetos de suínos e de palhas de cereais é um processo ainda relativamente pouco estudado no Brasil. O objetivo deste trabalho foi avaliar a mineralização do $\mathrm{C}$ da palha de aveia, dos dejetos líquidos de suínos e da cama sobreposta de suínos, aplicados na superfície ou incorporados em um Argissolo Vermelho distrófico arênico, em condições de laboratório. Utilizou-se o delineamento inteiramente casualizado, com quatro repetições dos seguintes tratamentos: solo; solo + palha incorporada; solo + palha em superfície; solo + cama sobreposta incorporada; solo + cama sobreposta em superfície; solo + dejetos líquidos incorporados; solo + dejetos líquidos em superfície; solo + palha + dejetos líquidos incorporados; e solo + palha + dejetos líquidos em superfície. Durante 80 dias de incubação, a emissão de $\mathrm{CO}_{2}$ foi medida continuamente. Ao final desse período, observou-se que foram mineralizados 59 \% do $\mathrm{C}$ dos dejetos líquidos e apenas 23 \% do $\mathrm{C}$ da cama sobreposta. A incorporação dos materiais orgânicos ao solo não resultou em maior mineralização do $\mathrm{C}$, quando comparado à permanência desses na superfície do solo. $\mathrm{O} \mathrm{N}$ amoniacal, aplicado com os dejetos líquidos de suínos, não aumentou a mineralização do $\mathrm{C}$ da palha de aveia.
\end{abstract}

Termos de indexação: decomposição, atividade microbiana, adubos orgânicos, emissão de $\mathrm{CO}_{2}$.

\footnotetext{
(1) Parte da Tese de Doutorado do primeiro autor, apresentada ao Programa de Pós Graduação em Ciência do Solo, Universidade Federal de Santa Maria - UFSM. Trabalho apresentado no XXXI Congresso Brasileiro de Ciência do Solo, 2007 (Gramado, RS).

(2) Professor Adjunto do Departamento de Solos, Universidade Federal de Santa Maria (UFSM), Santa Maria, RS. CEP: 97.105900. E-mail: sjgiacomini@smail.ufsm.br

(3) Professor Associado do Departamento de Solos, UFSM. Bolsista do CNPq. E-mail: celsoaita@gmail.com

(4) Mestrando do Curso de Pós-Graduação em Agronomia, Universidade Federal de Pelotas, Pelotas, RS. CEP: 96010-900. Bolsista CAPES. E-mail: ezequielmiola@yahoo.com.br

(5) Pesquisadora do INRA, UMR614 FARE, F-51000 Reims, France. E-mail: sylvie.recous@reims.inra.fr
} 


\title{
SUMMARY: CARBONMINERALIZATION OF STRAW AND PIG MANURE WITH AND WITHOUT INCORPORATION IN SOIL
}

\begin{abstract}
The $C$ mineralization of pig manure and cereal straw is still relatively little studied in Brazil. The aim of this work was to evaluate $C$ mineralization of oat straw, pig slurry and pig deep-litter, applied on the surface or incorporated in a Hapludalf soil, in laboratory conditions. The experiment was a completely randomized design with four replications of the following treatments: soil; soil + incorporated straw; soil + surface straw; soil + incorporated pig deep-litter; soil + surface pig deep-litter; soil + incorporated pig slurry; soil + surface pig slurry; soil + incorporated straw + pig slurry; and soil + surface straw + pig slurry. During the 80 days of incubation, the $\mathrm{CO}_{2}$ emission was measured continuously. After this period, 59 $\%$ of pig slurry $C$ had been mineralized and only $23 \%$ of deep-litter $C$. The soil incorporation of organic materials did not result in higher $C$ mineralization, compared with organic material on the soil surface. Ammoniacal $N$, applied with pig slurry did not increase $C$ oat straw mineralization.
\end{abstract}

Index terms: decomposition, microbial activity, organic fertilizers, $\mathrm{CO}_{2}$ emission.

\section{INTRODUÇÃO}

Com a crescente expansão do sistema plantio direto na região sul do Brasil, é cada vez mais comum a aplicação de dejetos líquidos de suínos diretamente sobre os resíduos culturais de espécies de inverno, como trigo e aveia, antecedendo a instalação das culturas de verão, especialmente, milho e feijão. Por ser esta uma modalidade de aplicação dos dejetos relativamente recente, pouco se conhece ainda sobre os seus efeitos na dinâmica de decomposição, tanto dos resíduos culturais como dos próprios dejetos.

Os dejetos líquidos de suínos são ricos em $\mathrm{N}$ amoniacal e, quando aplicados sobre resíduos culturais com elevada relação $\mathrm{C} / \mathrm{N}$, como aqueles de cereais, poderão aumentar a velocidade de decomposição dos mesmos no solo, por ser a assimilação de $\mathrm{C}$ pelos microrganismos decompositores acompanhada pela assimilação simultânea de N (Recous et al., 1995). Esse processo foi avaliado por Saviozzi et al. (1997) e Chantigny et al. (2001), que incorporaram palha de cereais ao solo, juntamente com dejetos de suínos, e observaram que os dejetos aumentaram a mineralização do $\mathrm{C}$ da palha, graças ao estímulo proporcionado pelo $\mathrm{N}$ amoniacal dos dejetos sobre a atividade da população microbiana decompositora. No entanto, Aita et al. (2006) verificaram que, em condições de campo e em plantio direto, a aplicação de dejetos líquidos de suínos não alterou a decomposição da palha de aveia. Para os autores, essa ausência de sinergismo entre dejetos e palha ocorreu, provavelmente, pelo fato de que as chuvas ocorridas logo após a aplicação dos dejetos carrearam o $\mathrm{N}$ mineral dos mesmos para além da zona de decomposição ativa dos compostos carbonados da palha de aveia. Além disso, a não- incorporação dos materiais orgânicos ao solo pode ter dificultado o acesso dos microrganismos ao $\mathrm{C}$ da palha, conforme também foi observado por Coppens (2005). Tais resultados contraditórios indicam que diversos fatores podem estar influenciando a decomposição da palha e dos dejetos quando aplicados conjuntamente, evidenciando a necessidade de intensificar estudos nessa área.

O manejo dos dejetos de suínos tem sido realizado, tradicionalmente, na forma líquida, reunindo fezes, urina, água de lavagem das instalações e sobras de alimentos fornecidos aos animais. Todavia, na última década, essa forma de manejo vem sendo substituída em muitas propriedades do sul do Brasil pelo sistema de manejo em cama sobreposta, em que os animais permanecem sobre uma camada de maravalha, serragem ou casca de arroz. Por ser relativamente recente no Brasil, há carência de informações referentes à dinâmica de decomposição no solo do material orgânico resultante desse sistema de criação dos animais.

A necessidade de melhor compreender a dinâmica do $\mathrm{C}$ durante a decomposição de dejetos de animais e de resíduos culturais está ligada à manutenção e melhoria da capacidade produtiva do solo, bem como à questão ambiental, uma vez que o principal produto da decomposição em condições aeróbias é o $\mathrm{CO}_{2}$, cuja contribuição para o aquecimento global pelo efeito estufa já é bem conhecida. Além disso, se os dejetos favorecerem a decomposição da palha, mais rapidamente o solo ficará descoberto e, portanto, estará mais susceptível aos efeitos erosivos da chuva. Nesse contexto, o presente trabalho teve como principal objetivo avaliar a mineralização do C de palha de aveia, dejetos líquidos e cama sobreposta de suínos aplicados na superfície ou incorporados ao solo. 


\section{MATERIAL E MÉTODOS}

O trabalho foi realizado no Laboratório de Microbiologia do Solo e do Ambiente do Departamento de Solos da Universidade Federal de Santa Maria (UFSM) - RS. Para a incubação, utilizou-se um Argissolo Vermelho distrófico arênico, coletado na camada de 0-10 cm de uma área que vinha sendo manejada em sistema plantio direto. Após a retirada dos resíduos culturais remanescentes na superfície, o solo foi homogeneizado e peneirado em malha de $4 \mathrm{~mm}$, sendo armazenado úmido em sacos plásticos, em temperatura ambiente, por 13 dias até o momento da incubação. No momento da coleta, o solo apresentou $150 \mathrm{~g} \mathrm{~kg}^{-1}$ de argila, $\mathrm{pH}$ em água de 5,2 e $18 \mathrm{~g} \mathrm{~kg}^{-1} \mathrm{de}$ matéria orgânica.

A aveia foi coletada no estádio de maturação fisiológica, submetida à secagem ao ar e armazenada em lugar seco até o momento da incubação. Os grãos de aveia foram descartados, antes da incubação, com a finalidade de diminuir a variabilidade entre as amostras incubadas e de obter uma palha com características químicas próximas daquelas encontradas no campo após a colheita mecânica dessa cultura. Os colmos e as folhas foram cortados em pedaços de $1 \mathrm{a} 2 \mathrm{~cm}$. Uma subamostra do material vegetal foi colocada em estufa a $65^{\circ} \mathrm{C}$, a fim de obter a matéria seca para calcular a quantidade de palha seca ao ar por adicionar ao solo. No material seco e moído, foram determinados os teores de $\mathrm{N}$ total e $\mathrm{C}$, conforme Tedesco et al. (1995).

Os dejetos utilizados foram obtidos em dois sistemas distintos de criação de suínos. Os dejetos líquidos (DL) foram coletados em uma esterqueira anaeróbia de uma unidade com animais de maternidade e recria, enquanto a cama sobreposta
(CS) foi coletada após terem sido criados cinco lotes de suínos de terminação (15 meses) sobre uma cama de maravalha.

A matéria seca dos dejetos foi determinada após a secagem desses em estufa a $65^{\circ} \mathrm{C}$ até peso constante. No material seco e moído, foram determinados os teores de C orgânico (Tedesco et al., 1995). Nos DL, os teores de $\mathrm{N}$ total e de $\mathrm{N}$ amoniacal $\left(\mathrm{N}_{-} \mathrm{NH}_{4}{ }^{+}+\mathrm{N}-\mathrm{NH}_{3}\right)$ foram determinados, conforme Aita et al. (2006), sem secagem prévia dos mesmos. Na CS úmida, os teores de $\mathrm{N}$ total, $\mathrm{N}$ amoniacal e $\mathrm{N}$ nítrico $\left(\mathrm{N}^{-} \mathrm{NO}_{2}{ }^{-}+\mathrm{N}\right.$ $\mathrm{NO}_{3}{ }^{-}$) foram determinados em $1 \mathrm{~g}$ de material, conforme Tedesco et al. (1995). Nos DL, a determinação do $\mathrm{pH}$ foi realizada diretamente em uma alíquota de aproximadamente $60 \mathrm{~mL}$ de dejetos, enquanto na CS, o pH em água foi determinado misturando-se dejetos e água destilada na proporção de 1:1 (Tedesco et al., 1995). As características e a quantidade adicionada de palha, DL e CS estão apresentadas no quadro 1.

O delineamento experimental utilizado foi o inteiramente casualizado com quatro repetições e nove tratamentos, sendo: T1 - Solo (S); T2 - Solo + palha incorporada (S + P Inc); T3 - Solo + palha em superfície (S + P Sup); T4 - Solo + cama sobreposta incorporada (S + CS Inc); T5 - Solo + cama sobreposta em superfície (S + CS Sup); T6 - Solo + dejetos líquidos incorporados (S + DL Inc); T7 - Solo + dejetos líquidos em superfície (S + DL Sup); T8 Solo + palha incorporada + dejetos líquidos incorporados (S + P Inc + DL Inc); e T9 - Solo + palha superfície + dejetos líquidos em superfície (S + P Inc + DL Sup). Os tratamentos foram acondicionados em incubadora na ausência de luz e temperatura de $25^{\circ} \mathrm{C}$. A umidade do solo foi ajustada para a capacidade de campo e mantida nesse nível, mediante adição periódica de água.

Quadro 1. Composição física e química e quantidades adicionadas ao solo de matéria seca (MS), carbono e nitrogênio com os dejetos líquidos, cama sobreposta e palha de aveia

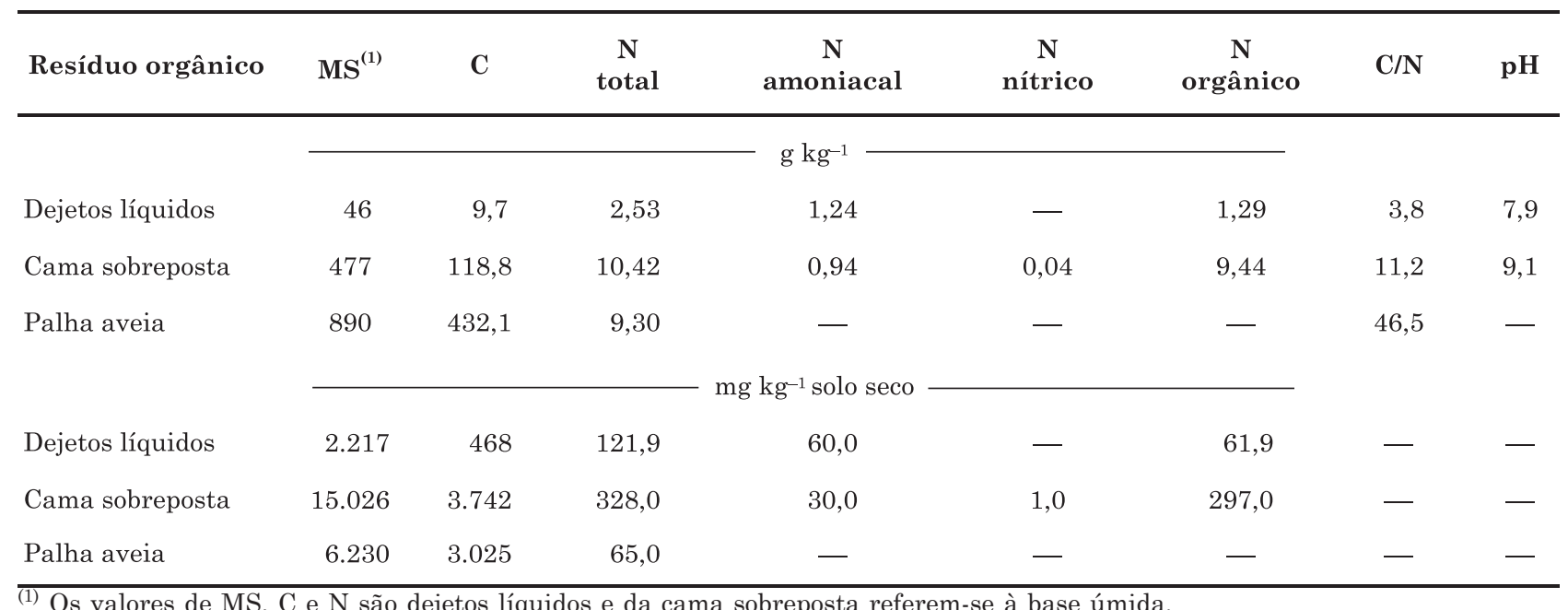


Cada unidade experimental foi montada separadamente. Em recipientes cilíndricos de acrílico, com $6,0 \mathrm{~cm}$ de altura e $5,3 \mathrm{~cm}$ de diâmetro interno, foram colocados $92,6 \mathrm{~g}$ de solo úmido ( $85,0 \mathrm{~g}$ solo seco a $105,0^{\circ} \mathrm{C}$ ), cuja umidade foi elevada à capacidade de campo. A altura da camada de solo dentro de cada recipiente foi de aproximadamente $5 \mathrm{~cm}$. A forma como o solo foi umedecido variou conforme o tratamento. Naqueles tratamentos em que os materiais orgânicos foram acrescentados à superfície do solo, adicionaramse em cada frasco de acrílico, 46,3 g de solo e, após, três $\mathrm{mL}$ de água. Em seguida, adicionaram-se o restante do solo (46,3 g) e, na superfície desse, os materiais orgânicos conforme os diferentes tratamentos. Com exceção dos tratamentos com DL, nos demais tratamentos, foram aplicados $4,1 \mathrm{~mL}$ de água sobre os resíduos orgânicos para atingir a capacidade de campo. Nos tratamentos com DL, o umedecimento do solo foi obtido através da fração líquida dos mesmos. Nos tratamentos com incorporação, o solo foi adicionado ao frasco de uma só vez $(92,6 \mathrm{~g})$ e, após, foram acrescentados $7,1 \mathrm{~mL}$ de água nos tratamentos sem $\mathrm{DL}$ e $3 \mathrm{~mL}$ de água nos tratamentos com DL. A mistura do solo úmido com os materiais orgânicos foi feita manualmente com auxílio de espátula.

A quantidade de palha de aveia acrescida a cada frasco foi de $7,0 \mathrm{~g} \mathrm{~kg}^{-1}$ de solo seco, equivalente a 2,8 $\mathrm{Mg} \mathrm{ha}^{-1}$ de palha. Antecedendo a incubação, a palha foi umedecida com água destilada na proporção de $3 \mathrm{~mL} \mathrm{~g}^{-1}$ de palha. Os DL e a CS foram adicionados nas proporções de $48,2 \mathrm{~mL} \mathrm{~kg}^{-1}$ de solo seco $\left(20 \mathrm{~m}^{3} \mathrm{ha}^{-1}\right)$ e $31,5 \mathrm{~g} \mathrm{~kg}^{-1}$ de solo seco $\left(12,6 \mathrm{Mg} \mathrm{ha}^{-1}\right)$, respectivamente. No caso dos DL, a quantidade adicionada foi estabelecida com a finalidade de evitar a saturação do solo pela fração líquida, além de proporcionar uma adição de $\mathrm{N}$ mineral de $60 \mathrm{mg} \mathrm{kg}^{-1}$ de solo que, segundo Recous et al. (1995), assegura uma condição nãolimitante de $\mathrm{N}$ à decomposição de palhas de cereais. A quantidade de CS foi estabelecida a fim de proporcionar uma adição próxima àquela realizada em condições de campo.

A mineralização do $\mathrm{C}$ nos diferentes tratamentos foi avaliada por meio da emissão de $\mathrm{C}-\mathrm{CO}_{2}$. Para isso, foram montadas 36 unidades experimentais (9 tratamentos $\mathrm{x} 4$ repetições), onde cada recipiente de acrílico foi acondicionado no interior de um frasco de vidro com capacidade de $800 \mathrm{~mL}$. Três unidades foram utilizadas como prova em branco, em que se colocou somente $\mathrm{NaOH}$, para captar o $\mathrm{C}-\mathrm{CO}_{2}$ presente no ar dos frascos. A avaliação da emissão de $\mathrm{C}-\mathrm{CO}_{2}$, durante a incubação, foi realizada sempre nas mesmas unidades experimentais. Para evitar que a deficiência de $\mathrm{O}_{2}$ limitasse a decomposição aeróbia dos materiais orgânicos, os frascos foram periodicamente abertos durante 15 min para aeração. $\mathrm{O} \mathrm{C}-\mathrm{CO}_{2}$ liberado em cada tratamento foi captado em $10 \mathrm{~mL}$ de uma solução de $\mathrm{NaOH} 1 \mathrm{~mol}$ $\mathrm{L}^{-1}$, cujo excesso foi titulado com uma solução de HCl 1 mol L$^{-1}$ (Stotzky, 1965). A medida da emissão de C- $\mathrm{CO}_{2}$ foi realizada aos $3,5,9,14,20,25,30,35$, 45, 55, 65 e 80 dias do início da incubação.

A mineralização do $\mathrm{C}$ da palha de aveia e dos dejetos de suínos foi calculada com base nos dados de C- $\mathrm{CO}_{2}$ medidos em cada data de avaliação. $\mathrm{O}$ cálculo da mineralização do C para os tratamentos com o uso isolado de palha e dejetos foi realizado com base na equação 1 e com o uso da palha conjuntamente com os dejetos com base na equação 2 , conforme segue:

$$
\begin{gathered}
M C=\left(\frac{\mathrm{CO}_{2} \mathrm{ro}-\mathrm{CO}_{2} \mathrm{~s}}{\mathrm{Cad}}\right) \times 100 \\
M C=\left(\frac{\mathrm{CO}_{2} \mathrm{cpd}-\mathrm{CO}_{2} \mathrm{~cd}}{\mathrm{Cadp}}\right) \times 100
\end{gathered}
$$

sendo $M C$ a mineralização do $\mathrm{C}$ da palha ou dos dejetos (\% do $\mathrm{C}$ adicionado); $\mathrm{CO}_{2}$ ro e $\mathrm{CO}_{2} \mathrm{~S}$ as quantidades de $\mathrm{C}-\mathrm{CO}_{2}$ emitidas $\left(\mathrm{mg} \mathrm{kg}^{-1}\right)$ nos tratamentos com o uso isolado de palha e dejetos de suínos e no tratamento testemunha (S), respectivamente; $\mathrm{Cad}$ o $\mathrm{C}$ adicionado $\left(\mathrm{mg} \mathrm{kg}^{-1}\right)$ com a palha ou com os dejetos; $\mathrm{CO}_{2} \mathrm{cpd}$ e $\mathrm{CO}_{2} \mathrm{~cd}$ as quantidades de $\mathrm{C}-\mathrm{CO}_{2}$ emitidas $\left(\mathrm{mg} \mathrm{kg}^{-1}\right)$ nos tratamentos com o uso conjunto de palha e dejetos e nos tratamentos com apenas o uso de dejetos, respectivamente; e Cadpo $\mathrm{C}$ adicionado $\left(\mathrm{mg} \mathrm{kg}^{-1}\right)$ com a palha.

Os resultados obtidos foram submetidos à análise da variância enquanto as médias de tratamentos foram comparadas pelo teste de Tukey a $5 \%$.

\section{RESULTADOS E DISCUSSÃO}

\section{Velocidade de mineralização dos materiais orgânicos}

Em todos os tratamentos avaliados, as taxas de mineralização do $\mathrm{C}$ foram maiores no início da incubação e diminuíram, gradativamente, até atingir valores praticamente constantes a partir de 65 dias (Figura 1). Tais resultados concordam com os obtidos por Saviozzi et al. (1997) e Coppens (2005). Essa dinâmica observada na decomposição de materiais orgânicos deve-se ao fato de que, na fase inicial da decomposição, são mineralizados os compostos carbonados mais lábeis, presentes na fração solúvel em água. Após a exaustão dessa fração, ocorre a mineralização gradativa e a taxas mais constantes dos compostos mais resistentes ao ataque microbiano.

Comparando os tratamentos com o uso exclusivo de materiais orgânicos, observa-se que, nos dejetos líquidos (DL) e cama sobreposta (CS), a taxa de liberação de $\mathrm{C}-\mathrm{CO}_{2}$ foi inferior àquela da palha de aveia (Figura 1). Considerando que a adição de $\mathrm{C}$ ao solo por meio da palha e da CS foi próxima (Quadro 1), é provável que a diferença observada na liberação 
de $\mathrm{C}-\mathrm{CO}_{2}$ entre esses dois materiais se deva a sua composição bioquímica diferenciada. Já no caso dos $\mathrm{DL}$, a menor liberação de $\mathrm{C}-\mathrm{CO}_{2}$ deve estar relacionada com a menor adição de $\mathrm{C}$ já que ela foi cerca de 6,5 vezes inferior à adição de $\mathrm{C}$ com a palha e a CS (Quadro 1). Analisando apenas os tratamentos com o uso exclusivo de DL e CS, observou-se que a taxa de liberação de $\mathrm{C}-\mathrm{CO}_{2}$, no início do experimento, foi semelhante entre os dois materiais orgânicos e que, a partir de 14 dias a CS superou o DL. A maior quantidade de $\mathrm{C}$ adicionado com a CS e a provável presença de uma fração de $\mathrm{C}$ facilmente decomposta nos DL podem explicar esses resultados.

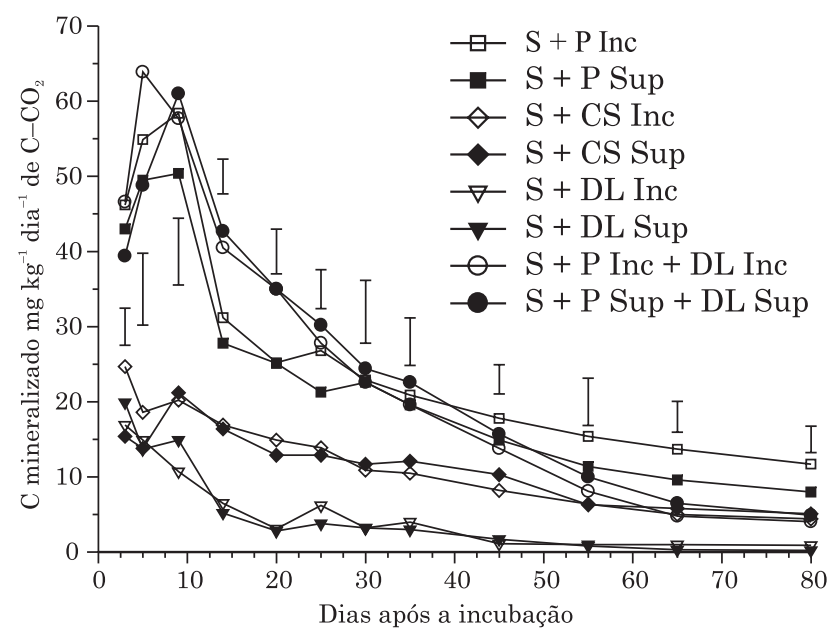

Figura 1. Velocidade de mineralização do C da palha de aveia (P), dos dejetos líquidos (DL) e da cama sobreposta (CS) utilizados isoladamente ou em conjunto, na superfície (Sup) ou incorporados (Inc) ao solo. As barras verticais representam a diferença mínima significativa entre as médias de cada tratamento (Tukey a $5 \%$ ).

Quanto ao efeito da incorporação dos materiais orgânicos, observa-se que a mineralização do C não foi favorecida pela sua incorporação ao solo. Esperavase que, principalmente na palha de aveia, cujo teor de N é baixo (Quadro 1) a sua incorporação favorecesse a mineralização do $\mathrm{C}$ pelo fato de aumentar o contato entre o solo e a palha, favorecendo o acesso dos microrganismos ao $\mathrm{C}$ e a difusão de $\mathrm{N}$ do solo até os sítios de decomposição junto à palha.

Contrariamente aos tratamentos com DL e CS, em que a taxa de liberação de $\mathrm{C}-\mathrm{CO}_{2}$ diminuiu ao longo do tempo, naqueles com palha a taxa de liberação de $\mathrm{CO}_{2}$ aumentou da primeira para a terceira avaliação (Figura 1). Tal resultado deve estar ligado à fase de adaptação da população microbiana ao substrato, onde ocorre a síntese de enzimas e outros compostos para a sua degradação. Observou-se uma tendência de essa fase ser mais pronunciada nos tratamentos em que a palha foi mantida na superfície do solo. Nessa condição, a colonização microbiana do substrato é mais lenta, dado o menor contato entre os resíduos e o solo, quando comparado aos resíduos incorporados ao solo (Coppens, 2005).

O efeito dos DL sobre a decomposição da palha pode ser avaliado comparando os tratamentos com a mesma modalidade de uso da palha. Observa-se que os dejetos líquidos proporcionaram aumento na liberação de $\mathrm{C}-$ $\mathrm{CO}_{2}$ da palha apenas na fase inicial do experimento. É provável que, nessa fase, tenha ocorrido a decomposição dos compostos orgânicos da fração solúvel da palha, a qual é degradada principalmente por bactérias que apresentam alta demanda em $\mathrm{N}$ (Sylvia et al., 1998). O N aplicado com os dejetos deve ter atendido tal demanda, o que favoreceu a decomposição dessa fração.

\section{Mineralização do C dos dejetos líquidos e da cama sobreposta de suínos}

A adição ao solo de CS e DL aumentou a liberação de $\mathrm{C}-\mathrm{CO}_{2}$ em relação ao solo sem a adição de materiais orgânicos (Figura 2), como resultado do metabolismo respiratório da população microbiana heterotrófica. Observa-se, ainda, que as quantidades de $\mathrm{C}$ mineralizadas, nos tratamentos com CS, foram significativamente maiores do que aquelas encontradas nos tratamentos com DL. Isso se deve principalmente à maior adição de $\mathrm{C}$ ao solo mediante CS (Quadro 1).

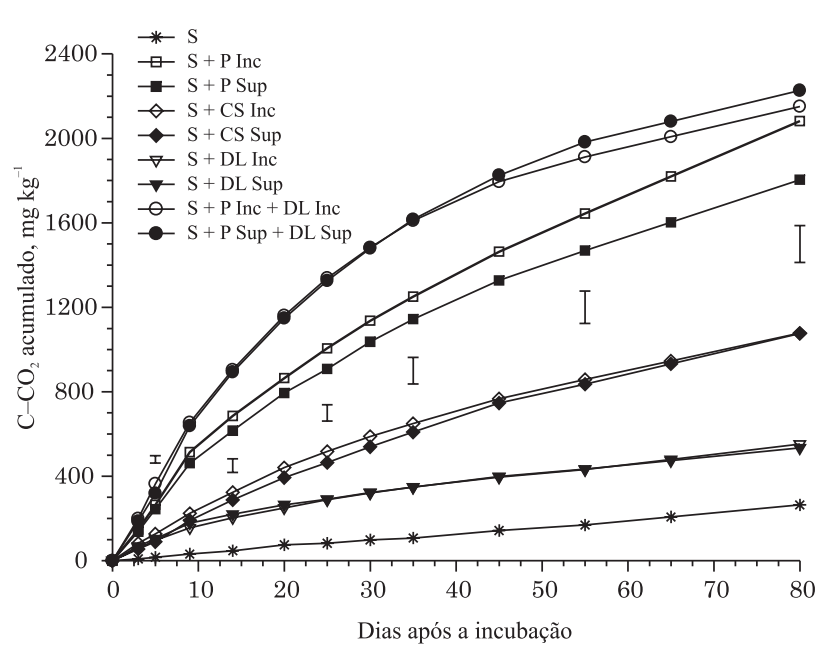

Figura 2. Quantidades acumuladas de C mineralizado do solo (S) e da palha de aveia (P), dos dejetos líquidos (DL) e da cama sobreposta (CS) utilizados isoladamente ou em conjunto, na superfície (Sup) ou incorporados (Inc) ao solo. As barras verticais representam a diferença mínima significativa entre as médias de cada tratamento (Tukey a $5 \%$ ). 
A mineralização do C dos DL apresentou uma fase inicial rápida, em que a quantidade de $\mathrm{C}$ mineralizada nos primeiros nove dias de incubação correspondeu a cerca de $30 \%$ da quantidade total de $\mathrm{C}$ mineralizada nos 80 dias (Figura 3). Já, na CS, a mineralização do $\mathrm{C}$ foi mais lenta desde o início da incubação. Essa elevada liberação de $\mathrm{C}-\mathrm{CO}_{2}$ nos primeiros dias no $\mathrm{DL}$ pode ser atribuída à decomposição do $\mathrm{C}$ presente na fração solúvel dos mesmos e, principalmente, à liberação do $\mathrm{C}-\mathrm{CO}_{2}$ presente inicialmente nos dejetos de suínos e àquele liberado a partir do $\mathrm{HCO}_{3}{ }^{-} \mathrm{e} \mathrm{CO}_{3}{ }^{2-}$ formados durante o armazenamento dos DL. Essas duas formas de C inorgânico são geradas nas esterqueiras anaeróbias e têm como origem o $\mathrm{CO}_{2}$, gerado pela hidrólise da uréia e pela decomposição de ácidos orgânicos voláteis (Sommer \& Husted, 1995). O C inorgânico acumulado pode ser rapidamente liberado quando os dejetos de suínos com $\mathrm{pH}$ alcalino são aplicados em solos ácidos (Aita et al., 1996). Além disso, a fermentação dos DL em esterqueiras anaeróbias resulta na formação de compostos de baixo peso molecular, tais como os ácidos graxos voláteis que são facilmente decompostos (Kirchmann \& Lundvall, 1993).

Ao final dos 80 dias de incubação, a CS foi o material orgânico que apresentou a menor porcentagem de mineralização do $\mathrm{C}$ adicionado (23\%), enquanto os maiores valores foram encontrados nos DL ( $59 \%$ do $\mathrm{C}$ adicionado) (Figura 3). Esse valor de mineralização para o C dos DL é próximo ao obtido por Ajwa et al. (1994), de 58 \%, e superior ao encontrado por Saviozzi et al. (1997), de $44 \%$. Essa menor porcentagem de C mineralizado nos tratamentos com CS, comparada aos tratamentos com DL, está relacionada com a composição química desses materiais orgânicos. $\mathrm{Na}$ CS utilizada na incubação, aproximadamente $70 \%$ do C nela presente estava contido na maravalha (dados não mostrados), cuja relação $\mathrm{C} / \mathrm{N}$ e o teor de lignina são elevados. Além disso, a decomposição dos DL e da CS dependem do manejo a que esses materiais orgânicos foram submetidos antes da sua adição ao solo. No sistema com CS, os compostos orgânicos de fácil decomposição da mistura de dejetos e maravalha são degradados já no local de criação dos animais, em condições parcialmente aeróbias. Durante esse processo, ocorre a liberação de $\mathrm{C}-\mathrm{CO}_{2}$, a incorporação de $\mathrm{C}$ na biomassa microbiana e a formação de compostos humificados, com elevado grau de recalcitrância (Thomsen \& Olesen, 2000).

A incorporação dos DL e da CS não provocou aumento na mineralização do $\mathrm{C}$ presente nestes materiais orgânicos (Figura 3), indicando que ambos os resíduos orgânicos apresentam uma fração do C que é de difícil decomposição, independentemente do contato entre o $\mathrm{C}$ dos resíduos e os microrganismos do solo. Em condições de laboratório, Dendooven et al. (1998) também verificaram que a incorporação de dejetos líquidos de suínos ao solo não resultou em maior liberação de $\mathrm{C}-\mathrm{CO}_{2}$, quando comparada aos dejetos deixados na superfície do solo.

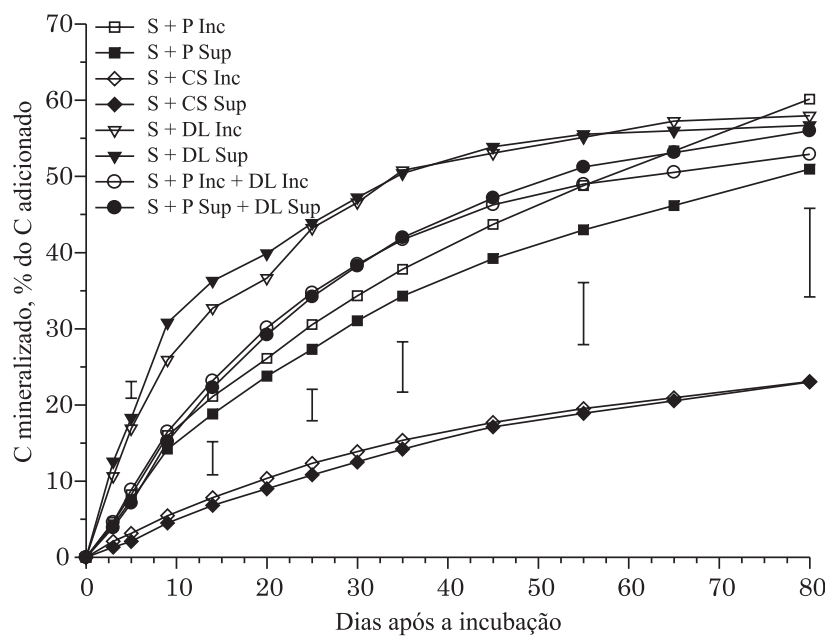

Figura 3. Carbono mineralizado da palha de aveia (P), dos dejetos de suínos (DL) e da cama sobreposta (CS) utilizados isoladamente ou em conjunto, na superfície (Sup) ou incorporados (Inc) ao solo. As barras verticais representam a diferença mínima significativa entre as médias de cada tratamento (Tukey a $5 \%$ ).

\section{Mineralização do C da palha de aveia}

As quantidades de $\mathrm{C}-\mathrm{CO}_{2}$ liberadas nos tratamentos que continham palha, com ou sem DL, superaram aquelas encontradas nos tratamentos com o uso exclusivo de DL e CS (Figura 2). Esse resultado, conforme discutido anteriormente, deve-se às diferenças na composição bioquímica dos materiais orgânicos e às diferentes quantidades de $\mathrm{C}$ adicionadas ao solo com os mesmos (Quadro 1).

Após 80 dias, a porcentagem do $\mathrm{C}$ da aveia que foi mineralizada variou de $51 \%$, no tratamento em que a palha foi utilizada isoladamente na superfície do solo $(\mathrm{S}+\mathrm{P}$ Sup), a $60 \%$, no tratamento com incorporação da palha (S + PInc), não havendo diferença significativa entre as duas modalidades de uso da palha (Figura 3). Nos tratamentos em que a palha e os DL foram adicionados juntamente e mantidos na superfície (S + P Sup + DL Sup) ou incorporados (S + P Inc + DL Inc) ao solo, o valor médio de mineralização do $\mathrm{C}$ da palha foi de $54,5 \%$, sem diferenças significativas entre incorporar ou não os materiais orgânicos ao solo. Esses valores obtidos para a mineralização do $\mathrm{C}$ da palha de aveia em superfície são superiores aos encontrados por Aita et al. (2006) em condições de campo, porém são próximos daqueles relatados por Recous et al. (1995) e Saviozzi et al. (1997) para palhas de cereais em condições de laboratório.

No presente trabalho, a mineralização do $\mathrm{C}$ da palha não foi alterada pela adição de $\mathrm{N}$ por meio dos dejetos líquidos de suínos nem pelo grau de contato entre a palha e o solo mediante a sua incorporação ou não (Figura 3). Essa ausência de efeito interativo na mineralização do $\mathrm{C}$ da palha, quando os dejetos e a 
palha foram incorporados conjuntamente no solo, está em desacordo com os resultados obtidos por Saviozzi et al. (1997), os quais verificaram que os dejetos aumentaram a decomposição da palha de trigo em $23 \%$. A maior relação $\mathrm{C} / \mathrm{N}$ da palha $(79,6)$ e a sua moagem fina no estudo de Saviozzi et al. (1997) devem ter contribuído para favorecer o efeito positivo dos dejetos sobre a decomposição da palha de trigo. Em dois experimentos de campo, em plantio direto, Aita et al. (2006) aplicaram dejetos líquidos de suínos sobre palhas de aveia, com relações $\mathrm{C} / \mathrm{N}$ de 43 e 45 e também verificaram que os dejetos não afetado a mineralização do $\mathrm{C}$ das duas palhas.

A magnitude do efeito da adição de $\mathrm{N}$ e do grau de contato sobre a decomposição de resíduos culturais depende principalmente da relação $\mathrm{C} / \mathrm{N}$ do material orgânico adicionado ao solo (Recous et al., 1995; Coppens, 2005). Quanto mais pobres em N (elevada C/N) forem os resíduos culturais, maior será a influência desses dois fatores sobre a sua decomposição no solo, já que o $\mathrm{N}$ aplicado e o contato dos resíduos culturais com o solo regulam a disponibilidade de $\mathrm{N}$ aos microrganismos que participam da sua decomposição. O grau de contato controla o fluxo de água e nutrientes, especialmente de $\mathrm{NO}_{3}{ }^{-}$, dos agregados do solo até os sítios de decomposição da palha (Coppens, 2005). Com base nessas informações, pode-se inferir que a relação $\mathrm{C} / \mathrm{N}$ de 46,5 da palha utilizada na presente incubação não foi suficientemente elevada para que sua decomposição fosse favorecida nem pela sua incorporação ao solo nem pela adição de $\mathrm{N}$ por meio dos dejetos. É provável que a quantidade de $\mathrm{N}$ presente na palha tenha atendido a demanda em $\mathrm{N}$ dos microrganismos atuantes na decomposição dos constituintes carbonados da mesma. Além disso, o $\mathrm{N}$ proveniente da mineralização da matéria orgânica do solo também pode ter contribuído para complementar as necessidades microbianas relativas a esse nutriente.

Outro fator que pode ter contribuído para a ausência de efeito da incorporação sobre a mineralização do $\mathrm{C}$ da palha refere-se às diferenças na composição da população microbiana atuante no processo de decomposição. Nos tratamentos em que a palha foi mantida na superfície do solo, observou-se o intenso crescimento de fungos (constatação visual). A capacidade dos fungos em colonizar os resíduos culturais na superfície do solo e absorverem o $\mathrm{N}$ mineral do solo, mediante suas hifas, foi demonstrada por Frey et al. (2000), o que pode ter contribuído para diminuir as diferenças encontradas nas quantidades de $\mathrm{C}$ mineralizadas entre os tratamentos com palha de aveia em superfície ou incorporada ao solo. Diferenças na quantidade e na composição da biomassa microbiana sob diferentes manejos dos resíduos culturais no solo é um aspecto ainda pouco investigado pelos pesquisadores.

Os resultados deste trabalho mostraram que a aplicação de dejetos líquidos de suínos, ricos em $\mathrm{N}$ amoniacal, sobre a palha de aveia não aumentou a mineralização do $\mathrm{C}$ da palha. Tal aspecto é positivo do ponto de vista da qualidade ambiental, uma vez que o uso dos dejetos sobre a palha de aveia, simulando o plantio direto, não aumentou a emissão de $\mathrm{CO}_{2}$ para a atmosfera, o que contribuiria para o aumento do efeito estufa. Todavia, é importante destacar que esses resultados foram obtidos em laboratório, onde a decomposição dos materiais orgânicos ocorre em condições ótimas de temperatura e umidade. Por isso, é importante intensificar os estudos relativos à avaliação do efeito dos dejetos sobre a mineralização do $\mathrm{C}$ da palha em condições de campo, comparando o sistema plantio direto ao preparo convencional do solo.

\section{CONCLUSÕES}

1. A aplicação dos dejetos líquidos de suínos juntamente com a palha de aveia, tanto incorporados como na superfície do solo, não aumentou a mineralização do $\mathrm{C}$ adicionado com a palha.

2. A incorporação dos dejetos líquidos de suínos, da cama sobreposta de suínos e da palha de aveia não aumentou a mineralização do $\mathrm{C}$ desses materiais orgânicos, quando comparada à sua manutenção na superfície do solo.

3. A proporção do $\mathrm{C}$ dos materiais orgânicos que foi mineralizada em 80 dias obedeceu à seguinte ordem: palha de aveia = dejetos líquidos de suínos $>$ cama sobreposta.

4. Ao Programa de Cooperação Internacional CAPES/COFECUB pelo auxílio financeiro concedido (Projeto 484/05/07).

\section{LITERATURA CITADA}

AITA, C.; CHIAPINOTTO, I.C.; GIACOMINI, S.J.; HÜBNER, A.P. \& MARQUES, M.G. Decomposição de palha de aveia preta e dejetos de suínos em solo sob plantio direto. R. Bras. Ci. Solo, 30:149-161, 2006.

AJWA, H.A. \& TABATABAI, M.A. Decomposition of different organic materials in soils. Biol. Fert. Soils, 18:175-182, 1994.

CHANTIGNY, M.H.; ROCHETTE, P. \& ANGERS, D.A. Shortterm $\mathrm{C}$ and $\mathrm{N}$ dynamics in a soil amended with pig slurry and barley straw: A field experiment. Canadian J. Soil Sci., 81:131-137, 2001.

COPPENS, F. Water, carbon and nitrogen dynamics in soil: Influence of crop residue location and quality. Leuven, Katholieke Universiteit Leuven, 2005. 203p. (Tese de Doutorado)

DENDOOVEN, L.; BONHOMME, E.; MERCKX, R. \& VLASSAK, K. Injection of pig slurry and its effects on dynamics of nitrogen and carbon in a loamy soil under laboratory conditions. Biol. Fert. Soils, 27:5-8, 1998. 
FREY, S.D.; ELLIOTT, E.T.; PAUSTIAN, K. \& PETERSON, G.A. Fungal translocation as a mechanism for soil nitrogen inputs to surface residue decomposition in a notillage agroecosystem. Soil Biol. Biochem., 32:689-698, 2000 .

KIRCHMANN, H. \& LUDVALL, A. Relationships between N immobilization and volatile fatty acids in soil after application of pig and cattle slurry. Biol. Fert. Soils, 15:161$164,1993$.

RECOUS, S.; ROBIN, D.; DARWIS, D. \& MARY, B. Soil inorganic $\mathrm{N}$ availability: Effect on maize residue decomposition. Soil Biol. Biochem., 27:1529-1538, 1995.

SAVIOZZI, A.; LEVI-MINZI, R.; RIFFALDI, R. \& VANNI, G. Role of chemical constituents of wheat straw and pig slurry on their decomposition in soil. Biol. Fert. Soils, 25:401-406, 1997.
SOMMER, S.G. \& HUSTED, S. The chemical buffer system in raw and digested animal slurry. J. Agric. Sci., 124:45-53, 1995.

STOTZKY, G. Microbial respiration. In: BLACK, C.A.; EVANS, D.D. \& WHITE, J.L., eds. Methods of soil analysis. Part 2. Madison, American Society of Agronomy, 1965. p.1550-1572.

SYLVIA, D.M.; FUHRMANN, J.J.; HARTEL, P.G. \& ZUBERER, D.A. Principles and applications of soil microbiology. New Jersey, Prentice Hall, 1998. 550p.

TEDESCO, M.J.; GIANELLO, C.; BISSANI, C.A.; BOHEN, H. \& VOLKWEISS, S.J. Análises de solo, plantas e outros materiais. Porto Alegre, Universidade Federal do Rio Grande do Sul, 1995. 174p.

THOMSEN, I.K. \& OLESEN, J.E. C and N mineralization of composted and anaerobically stored ruminant manure in differently textured soils. J. Agric. Sci., 135:151-159, 2000. 